\title{
SEASONAL CHANGE OF ORIBATID MITE COMMUNITIES (ACARI, ORIBATIDA) IN THREE DIFFERENT TYPES OF MICROHABITATS IN AN OAK FOREST
}

\author{
GergóCs, V. ${ }^{1}$ - GARAMVÖLGYI, Á. ${ }^{1}-$ HOMORÓdI, R. ${ }^{2}$ - HUFNAGEL, L. ${ }^{3 *}$ \\ ${ }^{1}$ Department of Mathematics and Informatics, Corvinus University of Budapest, Faculty of \\ Horticulture, H-1118 Budapest, Villányi út 29-43., Hungary \\ (phone: +36-1-482-6261; fax: +36-1-466-9273) \\ ${ }^{2}$ ALÖKI Applied Ecological Research and Forensic Institute Ltd. \\ H-1185 Budapest, Kassa utca 118.., Hungary \\ 3 "Adaptation to Climate Change" Research Group of the Hungarian Academy of Sciences- \\ Corvinus University of Budapest \\ H-1118 Budapest, Villányi út 29-43., Hungary \\ (phone: +36-1-482-6261; fax: +36-1-466-9273) \\ *Corresponding author \\ e-mail:leventehufnagel@gmail.com \\ (Received $9^{\text {th }}$ February 2011; accepted $27^{\text {th }}$ May 2011)
}

\begin{abstract}
Oribatid mites are one of the most abundant groups of the ground-dwelling mesofauna. They can be found in almost every terrestrial habitat all over the world and they are characterized by great species richness and great number of individuals. In spite of that not enough is known about their behaviour on community level and their spatial and temporal pattern in different habitats of the world. In our present study the seasonal behaviour of oribatid mite communities was analysed in three types of microhabitats in a temperate deciduous forest: in leaf litter, soil and moss. Samples were collected at a given site in a year and a half and the oribatid mite communities living there were studied on genus level along with the changes of meteorological factors characteristic of the area. The results show that corresponding to similar previous researches, the communities in our study do not have a seasonally changing, returning pattern either. Based on this, we can conclude that climatic differences and differences in other seasonally changing factors between the seasons do not have a significant role in the annual change of communities. Besides that we discovered that the communities of the three microhabitats are not completely the same. It is the oribatid mite community of the moss which differs mostly from communities in the leaf litter and in the soil. Our study calls attention among others to the fact that compositional changes of the oribatid mite communities living all over the world and their causes are unclear to date.
\end{abstract}

Keywords: oribatid mites, communities, microhabitats, seasonality, temperate deciduous forest

\section{Introduction}

In most habitats oribatid mites account for the biggest part of microarthropods (e.g. Schenker, 1986; Johnston and Crossley, 2002). They can be found in most terrestrial microhabitats: in soil, leaf litter, moss, underwood, foliage and in aquatic habitats as well (Behan-Pelletier, 1999). They can be found mostly in great species richness and abundance in their habitats (Behan-Pelletier, 1999). They play a significant role in decomposition processes because they fragment the organic matter and influence the biomass and species composition of fungi and bacteria (Wallwork, 1983; Seastedt, 1984; Yoshida and Hijii, 2005). As this group plays a significant role in soil processes, it is necessary to get to know its spatial pattern and the causes of pattern generation, which can be used later for indication (Behan-Pelletier, 1999). 
Several researches have already been done to detect the pattern and composition of oribatid mite communities and their exact causes. However, it is hidden to date by which mechanisms the structure and functioning of the individual communities are affected.

Climatic factors belong to the most determinant ones. The above statement is reflected by the number of researches as well, because most of the studies on oribatid mite communities investigate how the communities react to the meteorological factors changing naturally or artificially, especially to temperature and the amount of precipitation (Gergócs and Hufnagel, 2009). First it is worth investigating the effect of the natural changes of the climatic factors, and the most appropriate way to do this is to study the seasonal changes of the communities. The mistake in most of these studies is that the research on seasonality is conducted over a maximum of a year (e.g. Schenker, 1984), so it cannot be determined whether the observed phenomena occur similarly each year. The most significant research on this topic was conducted by Irmler (2006) in a beech forest in Germany. He investigated monthly changes of ground-dwelling oribatid mite communities over a seven-year period and found that there are no important changes among the communities.

Our research is similar to his one, however, it differs as well because we collected samples every two weeks and not once a month, and we investigated not one but three microhabitats over a one and a half year period in an oak forest in Hungary.

The other difference is that data on oribatid mites were recorded on genus level and not on species level. The decision on the genus level can be justified by several factors. The analysis of Caruso and Migliorini (2006) showed that there were not any important changes in the data when studying human disturbance on oribatid mites and changing from species level to genus level. Podani (1989) found a similar result in case of plants, namely, changing to genus level does not mean a significant difference when comparing the studied habitats. Osler and Beattie (1999), Hammer and Wallwork (1979) and Norton et al. (1993) concluded according to their studies that the many widespread genera and families indicate that the similarity between oribatid mite communities should be studied above species level. In their meta-analyses their assumption was confirmed that taxonomical levels above the species level are more suitable to compare habitats. According to this we also compared the data series recorded with time difference on genus level.

The aim of our study was to explore which seasonal changes occur in oribatid mite communities living in three types of microhabitats in an oak forest and what role the most important climatic factors that is the amount of precipitation and temperature have in these changes.

\section{Materials and methods}

Samples for our study were collected in 2005 and 2006 in a given quadrate of $100 \mathrm{~m}^{2}$ in a dry oak forest near Törökbálint, Hungary $\left(47^{\circ} 25^{\prime} 38^{\prime \prime} \mathrm{N}, 18^{\circ} 54^{\prime} 16^{\prime \prime} \mathrm{E}\right)$. In the sampling quadrate the most common tree species is turkey oak (Quercus cerris), common trees are field maple (Acer campestre), common ash (Fraxinus excelsior) and wild service tree (Sorbus torminalis). The most important herbaceous plants are broadleafed Solomon's seal (Polygonatum latifolium) and garlic mustard (Alliaria petiolata). Samples were collected every two weeks from $15^{\text {th }}$ March till $1^{\text {st }}$ December 2005 and from $26^{\text {th }}$ March till $30^{\text {th }}$ July 2006 . Every time samples were collected randomly from 
three types of substrate within the quadrate: from $500 \mathrm{~cm}^{3}$ leaf litter, $300 \mathrm{~cm}^{3}$ foerna (from under the leaf litter) and $0.5 \mathrm{dm}^{2}$ hypnum moss (Hypnum cupressiforme) living on tree trunks. So we obtained altogether 19 moss samples and 18 leaf litter and 18 foerna samples in 2005 (the first time no leaf litter and foerna samples were collected); in 2006 we collected 10 leaf litter, 10 moss and 9 foerna samples (the tenth sample could not be analyzed for technical reasons). Components of the mesofauna were extracted with the help of a modified Berlese-Tullgren funnel (Coleman et al., 2004) and conserved in isopropyl alcohol, then they were sorted into larger groups, and finally oribatid mites were identified on genus level. For the identification the works of Balogh (1965), Balogh and Balogh (1992, 1972), Balogh and Mahunka (1980), Olsanowski (1996) and Hunt et al. (1998) were used.

The samples were analyzed based on oribatid mite communities with the help of multivariate computer aided methods using the software Syn-tax 2000 (Podani, 2001). The size difference between the samples from the three types of substrate was compensated by comparing the ratio and presence-absence data of the oribatid mite genera with the help of non-metric multidimensional scaling and classification method using several distances. Monte Carlo method was used to check these analyses. The means of the genus proportion of the substrate types were calculated, each mean was multiplied by a number created by a random generator twenty times, then these new values were divided by the sum of the random numbers. This way twenty data series were generated per substrate. These were compared using classification and ordination. Correspondence analysis and PCA analysis were used to identify the genera which are responsible for possible differentiations. The difference of the genera in specimen number and proportion was checked using Mann-Whitney test between the substrate types. The average diversity and the genus number were calculated in case of each substrate type.

In order to recognize seasonality patterns, each season was marked (in winter no sampling was conducted), and the changes in genus diversity and total abundance during a period of the study were displayed separately in case of the three substrate types. The relationship between the pattern changes of the communities and meteorological factors was analyzed with the help of data series from the meteorological station in Pestszentlörinc $\left(47^{\circ} 25^{\prime} 53^{\prime \prime} \mathrm{N}, 1^{\circ} 10^{\prime} 57^{\prime \prime} \mathrm{E}\right)$. This station can be found 21 air $\mathrm{km}$ eastwards from our sampling point. In the case of precipitation the total precipitation amount of the sampling day and that of the preceding 5 and 10 days, and the standard deviation of the precipitation amount of the preceding 5, 10, 15, 20, 25 and 30 days were considered. In the case of temperature minimum and maximum values of the given days were available in our database, so in our analyses the means of these two values were considered. As for temperature data, the mean temperature of the sampling day and that of the preceding 5 and 10 days, and the standard deviation of temperature of the preceding $5,10,15,20,25$ and 30 days were involved in our analyses. A redundancy analysis was conducted for all substrates first and then separately. In order to make the relationships more exact, the correlation between certain genera and meteorological factors was studied based on Spearman's analysis.

\section{Results}

52 genera were found in the three types of substrate altogether, in leaf litter and foerna 48-48 genera and in moss only 30 occurred. According to the ordination and 
classification (Fig. 1) it can be stated that oribatid mite communities of the leaf litter and foerna do not differ from each other but they differ from moss samples. In these figures it can be seen as well that the samples collected in different times are completely mixed, the different markings of the three seasons are also mixed without a pattern in the figures, which confirms our assumption that no seasonal effects can be found in the case of oribatid mite genera.

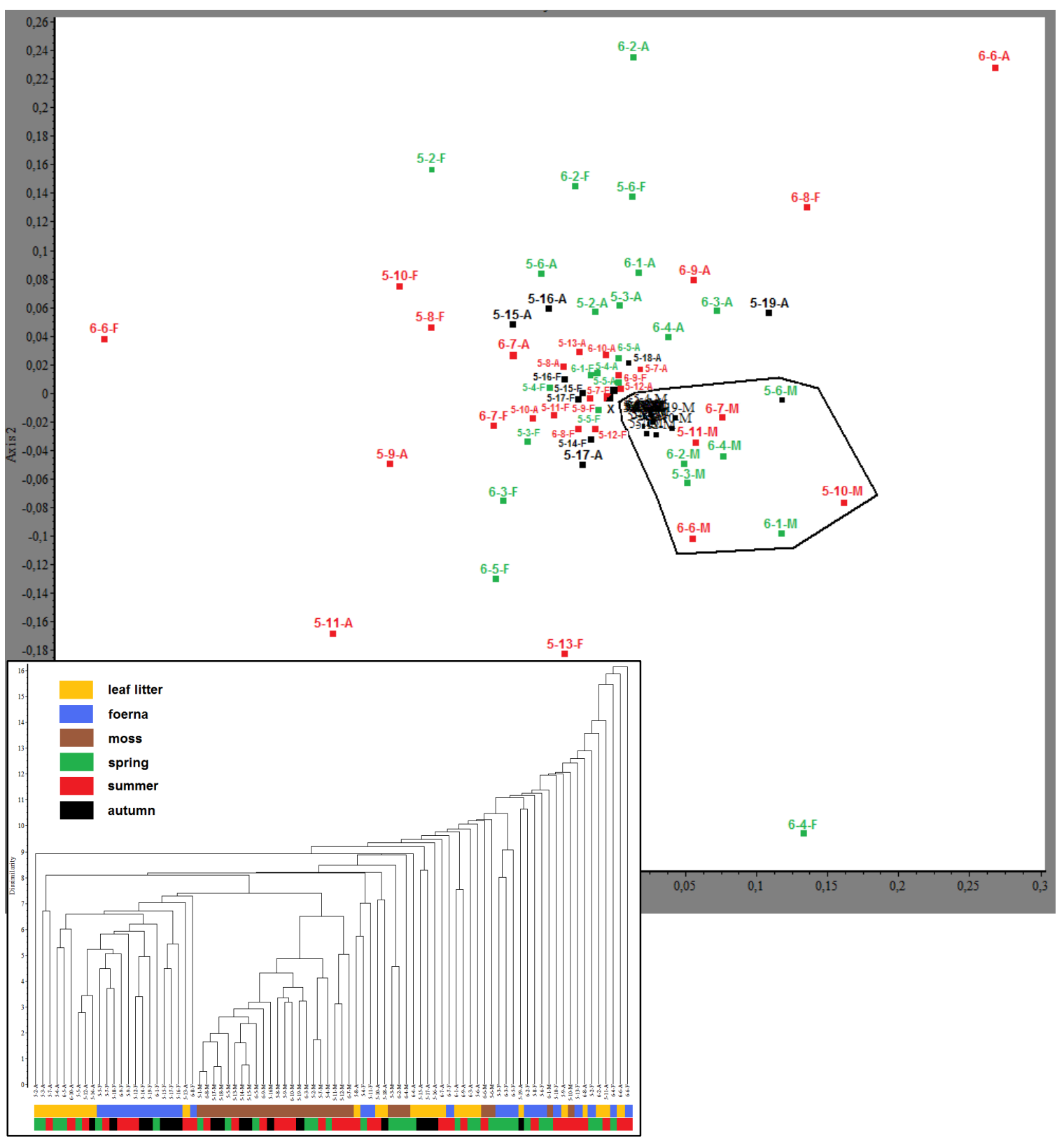

Figure 1. Large figure: Non-metric multidimensional scaling of the ratio of the genera and juvenile groups in the three substrates using Euclidean distance. The first number in the codes represents 2005 (5) or 2006 (6), the second one is the chronologic serial number of the samples and the third symbol in the code means the substrate. $M=$ moss, $F=$ foerna, A=leaf litter. Spring samples were marked with green, summer samples with red and autumn-winter samples with black colour. Moss samples are framed. X=5-14-A, 5-18-F, 5-19-F. Small figure:

Classification of the same series using group-average method with Euclidean distance. Considered groupings were marked with a colour code based on substrate types and seasons 
Monte Carlo experiments conducted in order to check the above analyses can be seen in Fig. 2. It shows that leaf litter and foerna substrates also differ from each other, however, not to the same degree as from the moss substrate.

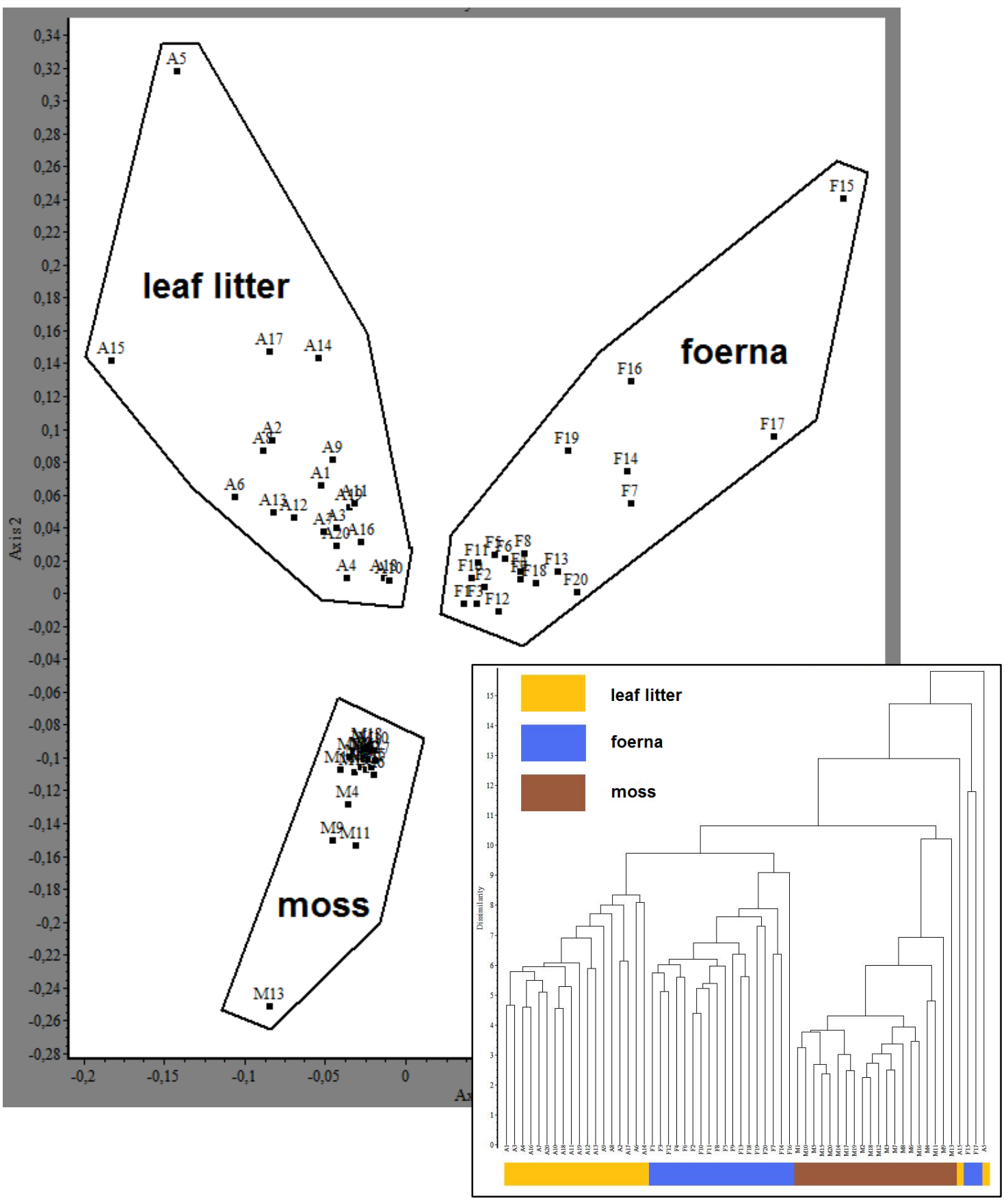

Figure 2. Large figure: Non-metric multidimesional scaling of the samples created with Monte Carlo method from the ratios of the three substrates: M1-20; A1-20; F1-20 (standardised Euclidean distance). Small figure: Classification of the same series using group-average method with standardised Euclidean distance. Separation of the three substrate types was marked with a colour code 
Separation of moss samples is mainly caused by their smaller genus diversity and smaller genus richness and by the fact that the following genera: Tectocepheus, Eremaeus, Zygoribatula and the juvenile group, to which larvae and nymphs belong, are present in a larger number here (Fig. 3). In moss samples 7, in leaf litter 19 and in foerna samples 22 genera were present on average during a period of one and a half years. Genus diversity of the samples from all three substrates differ from each other significantly $(\mathrm{p}<<0.01)$. Moss samples have the lowest diversity and foerna samples have the highest one (Table 1).

Table 1. Average diversity along with standard deviation in the three substrates during a period of one and a halfyears

\begin{tabular}{ccccc}
\hline & Foerna & Leaf litter & Moss \\
\hline $\begin{array}{c}\text { Shannon mean }( \pm \text { standard } \\
\text { deviation })\end{array}$ & $2.20( \pm 0.21)$ & $1.871( \pm 0.34)$ & $0.98( \pm 0.26)$ \\
$\begin{array}{c}\text { Simpson mean }( \pm \text { standard } \\
\text { deviation) }\end{array}$ & $0.82( \pm 0.07)$ & $0.73( \pm 0.11)$ & $0.52( \pm 0.10)$ \\
$\begin{array}{c}\text { Average number of genera } \\
21.7( \pm 4.5)\end{array}$ & $19.3( \pm 4.3)$ & $6.6( \pm 2.7)$ \\
\hline
\end{tabular}

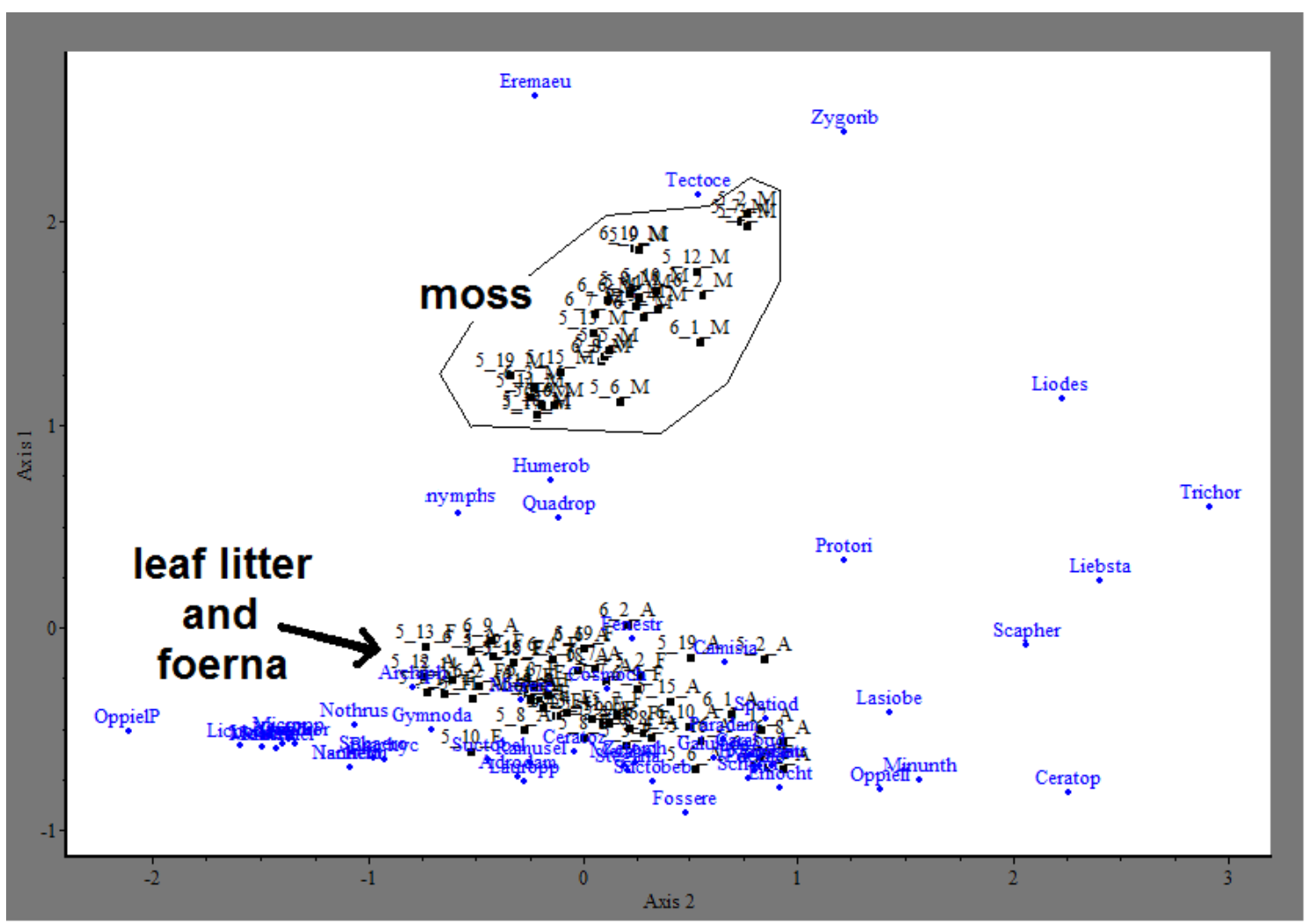

Figure 3. Correspondence analysis on the ratios of the genera and nymphs (juvenile group) in the three substrates

The proportions of the genera Tectocepheus and Zygoribatula and the juveniles in the three substrates can be seen in Table 2. The difference of these values in the three substrates was significant in all cases $(\mathrm{p}<<0.01)$. The genus Eremaeus occurred only in 
moss samples except for only one foerna sample, with 10.9 specimens on average, 15 times out of 29 , but with rather varying abundance and proportion in time. Besides the above, two other genera near the moss group: Humerobates and Quadroppia can be seen in Fig. 3. Humerobates is a rare component, and in the case of Quadroppia no difference was found between the proportions compared to the other two substrates.

Table 2. Proportions of Tectocepheus, Zygoribatula and the juveniles in the three substrates. The values in moss samples are highlighted because these values are significantly different from the values of the two other substrates.

\begin{tabular}{c|c|c|c}
\hline & Leaf litter & Foerna & Moss \\
\hline juvenile group / total & $0.188 \pm 0.106$ & $0.201 \pm 0.104$ & $0.397 \pm 0.206$ \\
number of specimens & $0.249 \pm 0.174$ & $0.280 \pm 0.169$ & $0.919 \pm 0.775$ \\
juvenile group / adults & $0.020 \pm 0.037$ & $0.017 \pm 0.020$ & $0.261 \pm 0.170$ \\
proportion of Tectocepheus & $0.017 \pm 0.023$ & $0.005 \pm 0.004$ & $0.230 \pm 0.187$ \\
\hline
\end{tabular}

The reason of the difference between foerna and leaf litter can be seen in the PCA analyses (Fig. 4). Table 3 represents in which genera the numbers of specimens and the ratios significantly differ between the two substrates. In all cases it can be shown that the genera displayed in Table 3 are present with larger abundance and relative abundance in foerna samples.

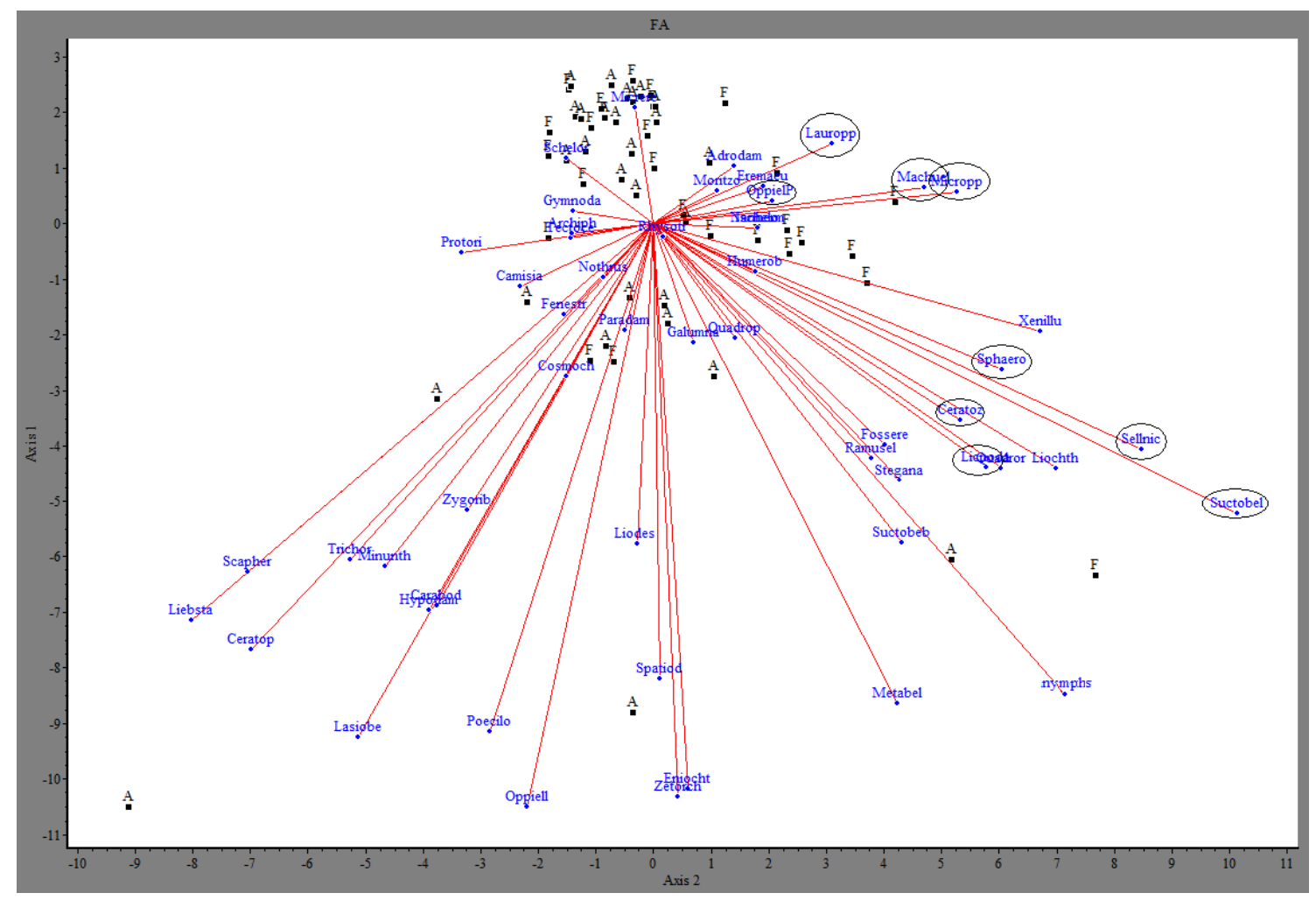

Figure 4. PCA analysis with the ratios of the juvenile group ("nymphs" in the figure) and the genera of the leaf litter and foerna samples (standardised). A=leaf litter, F=foerna; the first 7 letters of the genera are displayed and the genera, the abundance and proportion of which significantly differ from each other in the two types of substrate, are circled 
Table 3. Abundance and proportion of the genera causing the difference between leaf litter and foerna samples

\begin{tabular}{l|c|c|c|c|c|c}
\hline & \multicolumn{3}{|c|}{$\begin{array}{c}\text { with the numbers of } \\
\text { specimens }\end{array}$} & \multicolumn{3}{c}{ with proportions } \\
\hline \multicolumn{1}{c|}{ genera } & $\begin{array}{c}\text { leaf } \\
\text { litter }\end{array}$ & foerna & p(same) & $\begin{array}{c}\text { leaf } \\
\text { litter }\end{array}$ & foerna & p(same) \\
\hline Sellnickochthonius sp. & 0.8 & 2.3 & 0.028 & 0.0014 & 0.0043 & 0.025 \\
Ceratozetes sp. & 1.9 & 3.0 & 0.055 & 0.0048 & 0.0092 & 0.049 \\
Lauroppia sp. & 0.3 & 8.1 & $9.76 \mathrm{E}-08$ & 0.0012 & 0.0250 & $3.06 \mathrm{E}-07$ \\
Licnodamaeus sp. & 60.1 & 68.7 & 0.04 & 0.1323 & 0.1577 & 0.0604 \\
Machuella sp. & 0.1 & 2.4 & $1.05 \mathrm{E}-05$ & 0.0002 & 0.0058 & $9.19 \mathrm{E}-06$ \\
Microppia sp & 0.0 & 2.0 & $2.32 \mathrm{E}-05$ & 0.0002 & 0.0048 & 0.000034 \\
Oppiella (Perspicuoppia) sp. & 0.0 & 1.2 & 0.017 & 0.0001 & 0.0030 & 0.018 \\
Sphaerochthonius sp. & 7.2 & 11.4 & 0.002 & 0.0200 & 0.0274 & 0.0006 \\
Suctobelbella sp. & 11.8 & 29.5 & 0.0002 & 0.0298 & 0.0750 & $4.95 \mathrm{E}-05$ \\
\hline
\end{tabular}

Seasonal changes could not be detected in the communities of the three substrates. These results can be seen on Fig. 1 and 5-6. The second number in the codes of the samples in Fig. 1 (the large one) means the progress of time during the year. It can be observed well that the numbers do not form groups according to the date of sampling. This proves that the progress of time that is seasonality does not generate patterns in oribatid mite communities. In Fig. 5 change in the Shannon diversity of the genera in the case of the three substrates and in Fig. 6 change in abundance of the oribatid mites can be observed, however, a seasonal pattern recurring the following year cannot be detected.

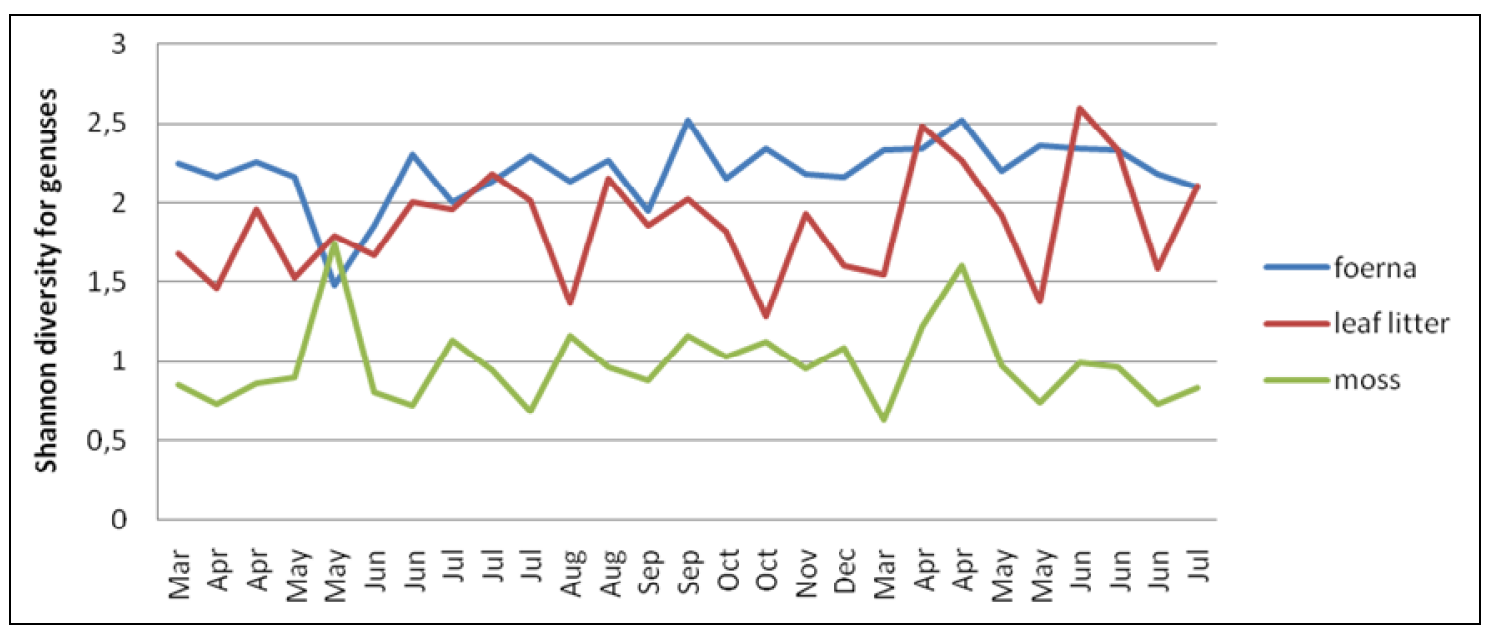

Figure 5. Change in the Shannon diversity of the genera in the case of the three substrates (2005-2006) 


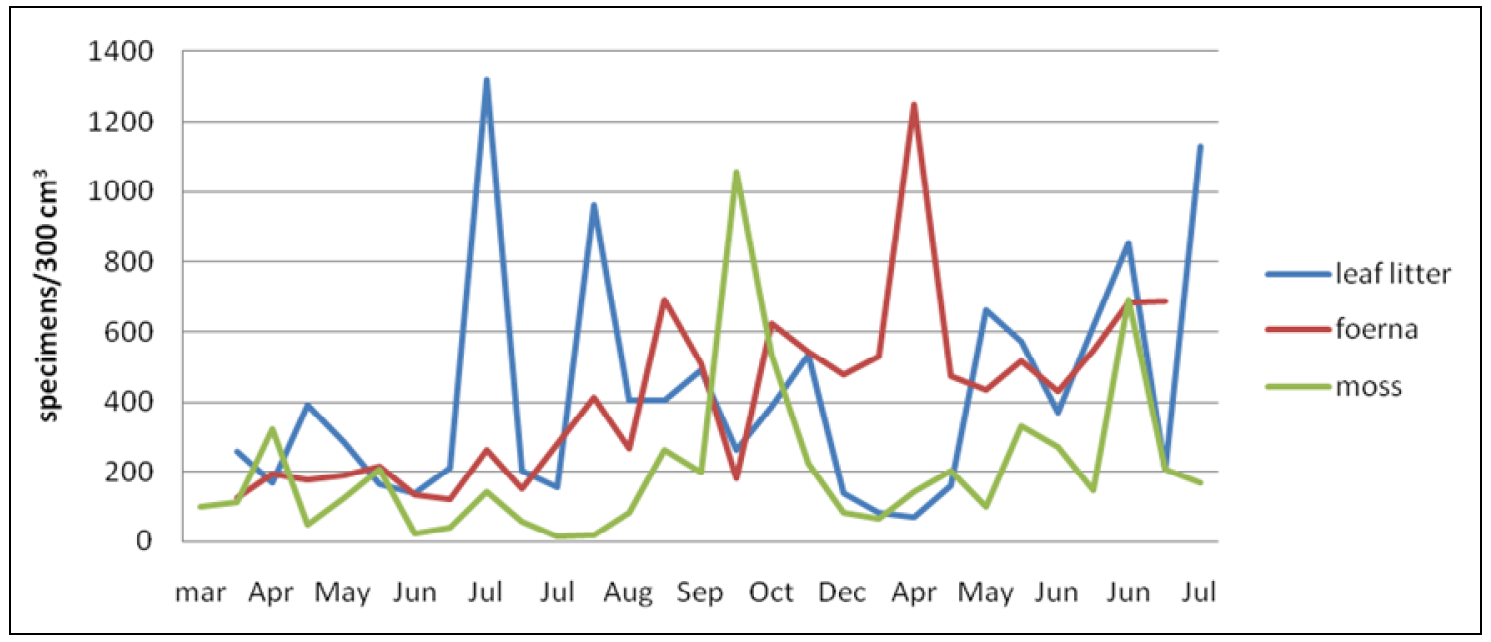

Figure 6. Change in abundance of the oribatid mites (2005-2006)

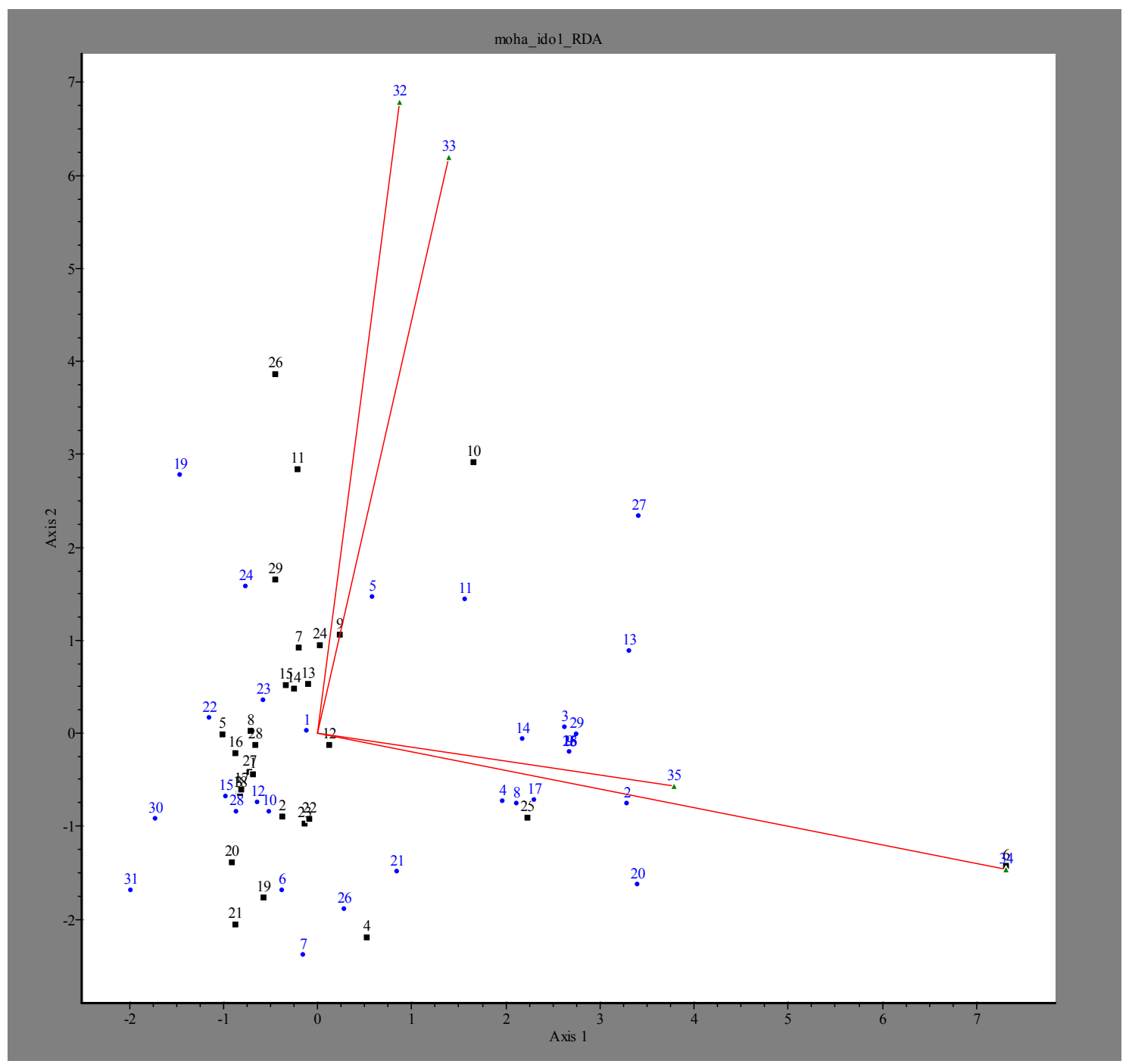

Figure 7. Redundancy analysis of moss samples collected during one and a half year regarding the precipitation amount and mean temperatures. (32: mean temperature (of 5 days); 33: mean temperature (of 10 days); 34: total amount of precipitation (in 5 days); 35: total amount of precipitation (in 10 days). The first axis is for $46 \%$ and the second one is for $31 \%$.)

APPLIED ECOLOGY AND ENVIRONMENTAL RESEARCH 9(2): 181-195. http://www.ecology.uni-corvinus.hu • ISSN 15891623 (Print) • ISSN 17850037 (Online)

(c) 2011, ALÖKI Kft., Budapest, Hungary 
We have not found any relationships between the annual changes in precipitation amount and temperature and the composition and structure of oribatid mite communities in leaf litter and foerna, however, in the case of moss we have. The result of the redundancy analysis is displayed in Fig. 7. The location of the samples is affected by mean temperature to a larger degree than by the precipitation amount. This can be caused by the genus Tectocepheus, which is one of the most frequent genera in moss samples ( $43 \%$ of the adult specimens on average), and its correlation is $\mathrm{r}=0.38$ regarding the five-day mean temperature (Spearman's correlation; $p=0.043$ ); and regarding the ten-day mean temperature its correlation is $\mathrm{r}=0.45$ (Spearman's correlation; $\mathrm{p}=0.014$ ) (Fig. 8).

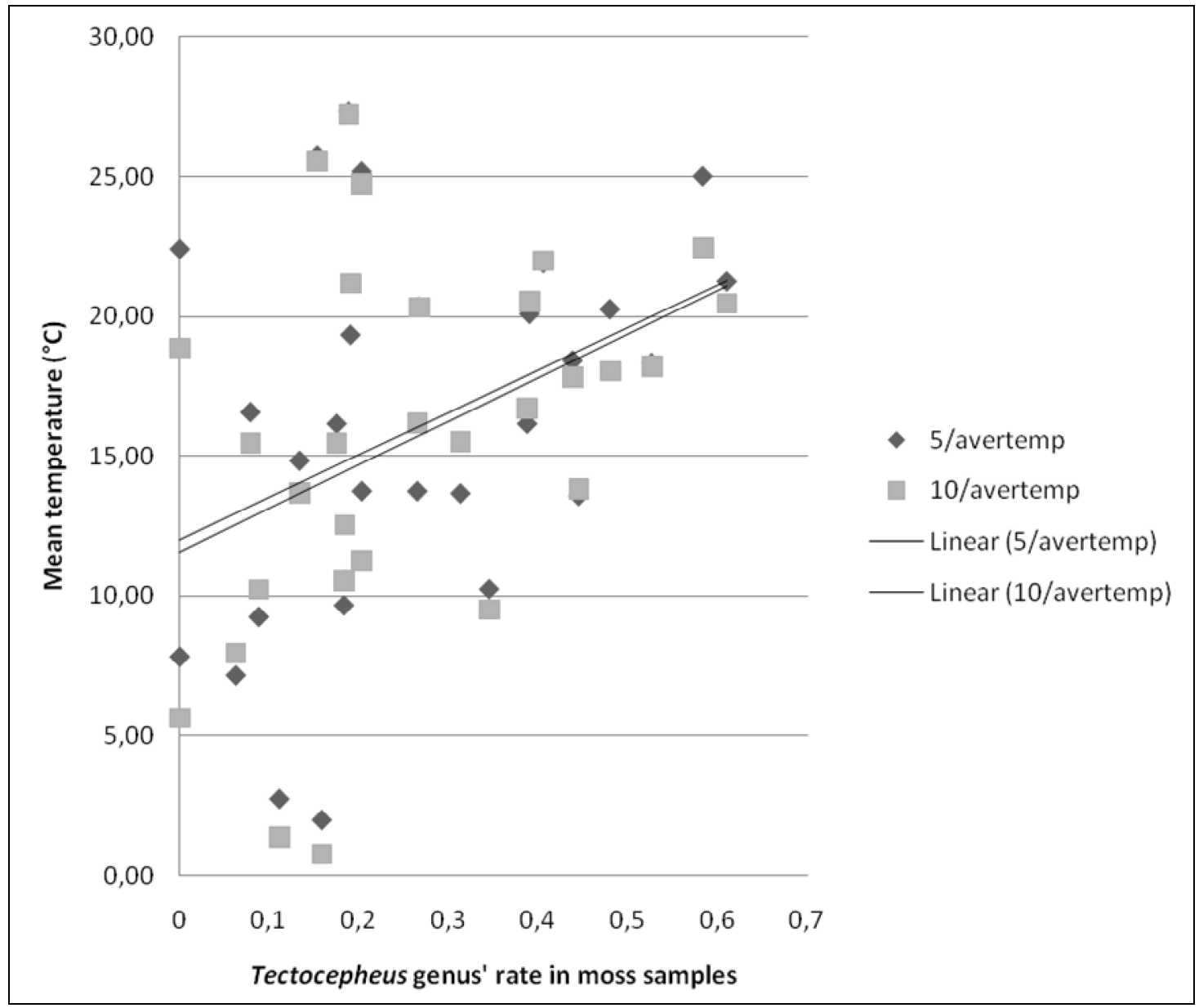

Figure 8. Correlation between the genus Tectocepheus' rate and the five-day and ten-day mean temperature

The most frequent groups within the moss are the genera Tectocepheus and Zygoribatula and the juvenile group. Table 4 shows that the ratio of the two most frequent genera is inversely proportional to the juvenile group that is the proportion of the juvenile group is only larger if the proportion of the two genera is smaller. The proportion of juveniles and adults changes during the one and a half year (Fig. 9), however, this pattern does not recur the following year, and it is not in connection either 
with the precipitation amount or with mean temperatures or with the values of standard deviation.

Table 4. Correlation and its observed p-values in the case of two genera (Tectocepheus and Zygoribatula) with the juvenile group in moss samples

\begin{tabular}{cccc}
\hline & \multicolumn{3}{c}{ correlation $\backslash$ p-values } \\
& juveniles & Tectocepheus & Zygoribatula \\
\hline juveniles & & 0.001398 & 0.010454 \\
Tectocepheus & -0.56524 & & 0.058951 \\
Zygoribatula & -0.46803 & -0.3548 & \\
\hline
\end{tabular}

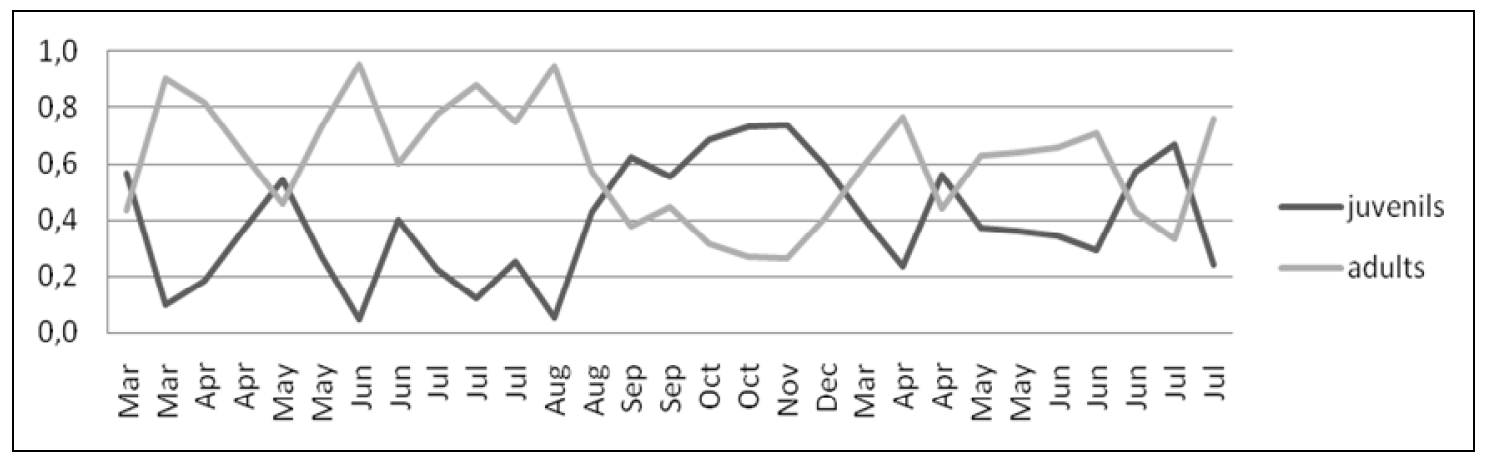

Figure 9. The proportion of juveniles and adults changes during the one and a half year

\section{Discussion}

According to the research in seasonality during one and a half year we conclude that if any change occurs in the community during the year, it is not seasonal, i.e. neither genus-level diversity, nor abundance, nor the structure of the community have a recurring pattern in leaf litter, foerna and moss microhabitats. These results correspond with several previous data from the literature. Irmler $(2004,2006)$ observed oribatid mite communities in two different habitats over several years and he did not find any seasonal regularity either, except for some species. Those who interpreted their results in a way that seasonal change was found in oribatid mite communities drew a conclusion based on only one studied year or on the difference between two sampling months (Schenker, 1984; Stamou and Sgardelis, 1989; Askidis and Stamou, 1991; Clapperton et al., 2002). Such a hypothesis was, among others that important changes may occur between two temperate seasons in oribatid mite communities (Stamou and Sgardelis, 1989; Askidis and Stamou, 1991; Clapperton et al., 2002). Although some of these studies were conducted in other types of habitats, i.e. not in temperate deciduous forests, a study covering a shorter period than a year is considered to be insufficient in the case of all habitats when observing regularities in seasonality. Schenker (1984) carried out a one year study around a turkey oak (Quercus cerris), a beech (Fagus sylvatica) and a Scots pine (Pinus sylvestris) in a moist deciduous forest in Switzerland. He found that annual change in abundance can be observed mostly around the beech and the pine, whereas it can hardly be observed around the oak, and species composition is not affected by seasonality, either. Oribatid mites occurred 
approximately in the same abundance further away from the oak trunks, than in the soil around it. For our study, data were collected in an oak forest. This may be the reason for the fact that we have not found any seasonal changes or changes in the genus composition, either. However, since Irmler (2006) conducted his studies in a beech forest and could not observe any seasonality either, and Schenker (1984) collected samples for only one year, it cannot be stated that the lack of seasonality is characteristic of oak forests.

If changes in communities do not occur seasonally, this can be brought into connection with micro- and macroclimatic effects. According to the results of Stamou and Sgardelis (1989) it could be concluded that the density of oribatid mites is largely influenced by temperature, although several later studies showed that temperature does not have the power to shape communities (Haimi et al., 2005). Irmler (2006) found that the structure of the community was in connection with the annual mean temperature only, and only some species showed significant correlation with some climatic factors. Webb et al. (1998) showed in the case of oribatid mite species living in polar areas that these species do not depend on seasonal changes, life cycle of the studied oribatid mite species is mainly influenced by temperature fluctuation. In our study proportional change correlating with temperature could be observed in the case of the genus Tectocepheus only and only in moss, however, no such connection can be found in the study of Irmler (2006), for example. Based on our results - just like based on those of Irmler (2006) - it can be concluded that the structure of oribatid mite communities is not affected by climatic factors in leaf litter and foerna substrates. In moss samples the connection with temperature was due to the genus Tectocepheus.

Seasonality can also be observed in the decomposition of plant material. Quantity and quality of the decomposing plant material change seasonally in the leaf litter and in the soil so it can be assumed that oribatid mite communities may change correspondingly during the year. However, the exact role of oribatid mites in the decomposition of the leaf litter is not completely clear till this day (Lindo and Winchster, 2007). The most important role of oribatid mites in the decomposition is the spreading of microbiota as they feed mainly on fungi and bacteria, and they are not in direct connection with the leaf litter input, accordingly (Maraun et al., 2001). This corresponds with the phenomenon observed by us, that the quantity of leaf litter may not have influenced the compositional changes of the communities.

Our result that leaf litter and foerna substrates differ from moss was not interpreted by other literature yet, however, there are observations regarding other types of substrates. A common result is for example that the oribatid mite community living in the foliage of the trees differs significantly from the one living in the soil under the trees (e.g. Yoshida and Hijji, 2005; Karasawa and Hijii, 2008). Karasawa and Hijii (2004) showed that the substrate of oribatid mite communities living in the soil, in the foliage, on the bark of the tree trunks and on the remnants of algae accumulating on soil significantly differ from each other in seaside forests. In our study the community living in hypnum moss was simpler than the one living in the soil in the forest. Communities of moss and lichen are always relatively simple (Gjelstrup, 1979; Gjelstrup and Søchtig, 1979; Smrz, 1992; Smrz and Kocourková, 1999; Smrz, 2006). The three frequent genera found in moss turned up in the observations of others as well. Zygoribatula exilis is assumed to be a species living in moss (Gjelstrup, 1979), however, the Zygoribatula species found by us could be found on the forest ground as well. The genus Tectocepheus occurs everywhere from drier and more disturbed habitats to intact 
forests, accordingly it can also be found in moss in great quantities, especially because climatic fluctuation is larger in moss, what only some species can tolerate (Gjelstrup, 1979). A common epiphyte is Eremaeus oblongus (Smrz and Kocourková, 1999), in our study the genus Eremaeus could be found only in moss (except for only one foerna sample).

Therefore our research showed that oribatid mite communities living in soil, leaf litter and hypnum moss, in Hungarian oak forests - similarly to those living in German beech forests - did not show seasonal changes. This result is important on the one hand because according to this, we are not bound to a season regarding sampling. However, besides that it would be important to detect the cause of the still occurring changes and patterns exactly. Furthermore it is unclear as well whether non-woody biocoenoses in the temperate zone or oribatid mite communities living in other climatic zones show seasonal changes.

Communities living in the soil differ from the oribatid mite community of moss living on tree trunks more significantly than from the community of the leaf litter. Oribatid mites in moss, especially the genus Tectocepheus, may be influenced by climatic factors to a large degree. In future it would be necessary to study oribatid mite communities of various microhabitats in order to detect exactly by which factors and to what degree their composition, changes and patterns are affected.

Acknowledgements. This work was supported by the Bolyai János Research Scholarship of MTA Doctoral Council, „ALÖKI” Applied Ecological Research and Forensic Institute Ltd., and the TÁMOP 4.2.1/B-09/1/KMR-2010-0005 project.

\section{REFERENCES}

[1] Askidis, M.D., Stamou, G.P. (1991): Spatial and temporal patterns of an oribatid mite community in an evergreen-sclerophyllous formation (Hortiatis, Greece). - Pedobiologia 35: 53-63.

[2] Balogh, J. (1965): A synopsis of the World Oribatid (Acari) Genera. - Acta Zoologica Academiae Scientiarum Hungaricae 9(1-2): 5-99.

[3] Balogh, J. (1972): The Oribatid Genera of the World. - Akadémiai Kiadó, Budapest.

[4] Balogh, J., Mahunka, S. (1980): ATKÁK XV-ACARI XV, Magyarország Állatvilága. Fauna Hungariae, XVIII. kötet, 19. füzet.

[5] Balogh, J., Balogh, P. (1992): The Oribatid Mites Genera of the World. - The Hungarian National Museum Press, Budapest.

[6] Behan-Pelletier, V.M. (1999): Oribatid mite biodiversity in agroecosystems: role for bioindication. - Agriculture, Ecosystems and Environment 74(1-3): 411-423.

[7] Caruso, T., Migliorini, M. (2006): Micro-arthropod communities under human disturbance: is taxonomic aggregation a valuable tool for detecting multivariate change? Evidence from Mediterranean soil oribatid coenoses. - Acta Eocologica 30(1): 46-53.

[8] Clapperton, M.J., Kanashiro, D.A., Behan-Pelletier, V.M. (2002): Changes in abundance and diversity of microarthropods associated with Fescue Prairie grazing regimes. Pedobiologia, 46(5): 496-511.

[9] Coleman, D.C., Crossley, Jr. D.A., Hendrix, P.F. (2004): Fundamentals of Soil Ecology. Chapter 9: Laboratory and Field Axercises in Soil Ecology. - Elsevier Academic Press, Burlington.

[10] Gergócs, V., Hufnagel, L. (2009): Application of Oribatid Mites as Indicators. - Applied Ecology and Environmental Research 7(1): 79-98. 
[11] Gjelstrup, P. (1979): Epiphytic cryptostigmatic mites on some beechand birch-trees in Denmark. - Pedobiologia 19: 1-8.

[12] Gjelstrup, P., Søchting, U. (1979): Cryptostigmatic mites (Acarina) associated with Ramalina siliquosa (Lichenes) on Bornholm in the Baltic. - Pedobiologia 19: 237-245.

[13] Haimi, J., Laamanen, J., Penttinen, R., Räty, M., Koponen, S., Kellomäki, S., Niemelä, P. (2005): Impacts of elevated $\mathrm{CO}_{2}$ and temperature on the soil fauna of boreal forests. Applied Soil Ecology 30(2): 104-112.

[14] Hammer, M., Wallwork., J.A. (1979): A review of tbe world distribution of oribatid mites (Acari: Cryptostigmata) in relation to continental drift. - Biol. Skrift. 22: 1-31.

[15] Hunt, G.S., Colloff, M.J., Dallwitz, M.J, and Walter, D.E. (1998): Oribatid mites: an interactive key to Oribatid mites of Australia. CD-ROM for MS-Windows. - CSIRO Publishing, Melbourne.

[16] Hunt, G.S., Norton, R.A., Kelly, J.P.H., Collof, M.J., Lindsay, S.M., Dallwitz, M.J., Walter, D.E. (1998): Oribatid mites: an interactive glossary to oribatid mites. CD-ROM for MS-Windows. - CSIRO Publishing, Melbourne.

[17] Irmler, U. (2004): Long-term fluctuation of the soil fauna (Collembola and Oribatida) at groundwater-near sites in an alder wood. - Pedobiologia 48(4): 349-363.

[18] Irmler, U. (2006): Climatic and litter fall effects on collembolan and oribatid mite species and communities in a beech wood based on a 7 years investigation. - European Journal of Soil Ecology 42(1): 51-62.

[19] Johnston, J.M., Crossley Jr. D.A. (2002): Forest ecosystem recovery in a southeast US: soil ecology as an essential component of ecosystem management. - Forest Ecology and Management 155(1-3): 187-203.

[20] Karasawa, S., Hijii, N. (2004): Effects of microhabitat diversity and geographical isolation on oribatid mite (Acari: Oribatida) communities in mangrove forests. Pedobiologia, 48(3): 245-255.

[21] Karasawa, S., Hijii, N. (2008): Vertical stratification of oribatid (Acari: Oribatida) communities in relation to their morphological and life-history traits and tree structures in a subtropical forest in Japan. - Ecological Research 23(1): 57-69.

[22] Lindo, Z., Winchester, N. (2007): Oribatid mite communities and foliar litter decomposition in canopy suspended soils and forest floor habitats of western redcedar forests, Vancouver Island, Canada. - Soil Biology and Biochemistry 39(11): 2957-2966.

[23] Maraun, M., Alphei, J., Beste, Ph., Bonkowski, M., Buryn,R., Migge, S., Peter, M., Schaefer, M., Scheu, S. (2001): Indirect effects of carbon and nutrient amendments on the soil meso- and microfauna of a beechwood. - Biology and Fertility of Soils 34(4): 222229.

[24] Norton, R.A., Kethley, J.B., Johnston, B.E., Oconnor, B.M. (1993): Phylogenetic perspectives on genetic systems and reproductive modes of mites. - In: Wrensch, D, and Ebbert, M. (eds) Evolution and diversity of sex ratio in insects and mites, Chapman and Hall.

[25] Olsanowski, Z. (1996): A monograph of the Nothridae and Camisiidae of Poland (Acari: Oribatida: Crotonoidea). - Genus International Journal of Invertebrate Taxonomy (Supplement), Wrocław.

[26] Osler, G.H.R., Beattie, A.J. (1999): Taxonomic and structural similarities in soil oribatid communities. - Ecography 22(5): 567-574.

[27] Podani, J. (1989): Comparison of ordinations and classifications of vegetation data. Vegetatio 83: 111-128.

[28] Podani, J. (2001): SYN-TAX 2000 user's manual. - Scientia Kiadó, Budapest.

[29] Schenker, R. (1984): Spatial and seasonal distribution patterns of oribatid mites (Acari: Oribatei) in a forest soil ecosystem. - Pedobiologia 27(22): 133-149.

[30] Seastedt, T.R. (1984): The role of microarthropods in decomposition processes. - Annual Review of Entomology 29: 25-46. 
[31] Smrž, J. (1992): The ecology of the microarthropod community inhabiting the moss cover of roofs. - Pedobiologia 36(6): 331-340.

[32] Smrž, J., Kocourková, J. (1999): Mite communities of two epiphytic lichen species (Hypogymnia physodes and Parmelia sulcata) in the Czech Republic. - Pedobiologia 43: 385-390.

[33] Smrž, J. (2006): Microhabitat selection in the simple oribatid community dwelling in epilithic moss cover (Acari: Oribatida). - Naturwissenschaften 93(11): 570-576.

[34] Stamou, G.P., Sgardelis, S.P. (1989): Seasonal distribution patterns of oribatid mites (Acari: Cryptostigmata) in a forest ecosystem. - Journal of Animal Ecology 58(3): 893904.

[35] Wallwork, J.A. (1983): Oribatids in forest ecosystems. - Annual Review of Entomology 28: 109-130.

[36] Webb, N.R., Coulson, S.J., Hodkinson, I.D., Block, W., Bale, J.S., Strathdee, A.T. (1998): The effects of experimental temperature elevation on populations of cryptostigmatic mites in high Arctic soils. - Pedobiologia 42(4): 298-308.

[37] Yoshida, T., Hijii, N. (2005): The composition and abundance of microarthropod communities on arboreal litter in the canopy of Cryptomeria japonica trees. - Journal of Forest Research 10(1): 35-42. 